\title{
sciendo
}

\section{Residential property price index in Croatia: from experimental to official statistics}

\author{
Davor Galinec \\ Croatian National Bank, Zagreb, Croatia \\ davor.galinec@hnb.hr \\ Jadranka Vuglar \\ Croatian National Bank, Zagreb, Croatia \\ jadranka.vuglar@hnb.hr \\ Dario Cvrtila \\ Dag Hammarskjöld University College of International Relations and \\ Diplomacy, Zagreb, Croatia \\ dario.cvrtila@diplomacija.hr
}

\begin{abstract}
:
The official statistics framework is based on internationally agreed standards, taking into account the core principles of impartiality, objectivity, professional independence, cost effectiveness, statistical confidentiality, minimisation of the reporting burden and high output quality. Since the latest 2007 global economic crisis, a growing demand for more, better and timelier data under limited resources for compilers and reporting agents has been observed. The concept of experimental statistics becomes more relevant, despite the lower quality in terms of coverage, data sources and harmonised definitions. The main aim of this paper is to present the methodological development of the residential property price index in Croatia from experimental to official statistics, as well as to show corresponding changes in time, which occurred due to the changes in methodological framework, institutional responsibility for compilation, coverage and data sources. A general conclusion of the paper is that publication of non-harmonized experimental statistics results, together with explanatory metadata, is better from the point of view of users than having nothing produced by official statistics.
\end{abstract}

Keywords: experimental statistics, hedonic regressions, residential property price index, residential real estate.

JEL code: C43, E31, R31.

DOI: $10.2478 /$ crebss-2019-0004

Received: October 10, 2018

Accepted: April 10, 2019

\section{Introduction}

Since the appearance of the most recent 2007 global economic crisis, and the following consequences, a growing demand for better, detailed and more timely data under limited resources for compilers, as well as reporting agents is observed. The 
concept of experimental statistics becomes more relevant and recognised as a new way of increasing the efficiency of official statistics production, despite the somewhat lower quality in terms of coverage, data sources, harmonised definitions and occasional heavy use of estimation techniques and expert assumptions. In this sense, dissemination of experimental statistics data is usually distinguished from official statistics data, using a clearly visible logo and accompanied by detailed methodological notes. The use of experimental statistics in the area of real estate can help statisticians bridge the limited availability of official data, in particular given its traditionally good timeliness that could provide a quick snapshot of currently perceived market conditions. Furthermore, experimental data could serve as a quality control for official data. Development of experimental statistics as a concept is enhanced by the G20 Data Gaps initiative. It is a collection of 20 recommendations on the enhancement of economics and financial statistics. The initiative was introduced with the aim to improve the availability and comparability of economics and financial data in the aftermath of 2007 Crisis, as a need of broader datasets available for policy makers and supervisors, in order to better assess the evolution of the economy, as well as the intervention required. The G20 became fully aware of the need of comprehensive and timely data and called on the IMF and on the Financial Stability Board (then called Financial Stability Forum) "to explore gaps and provide appropriate proposals for strengthening data collection". At the end of year 2008, the special inter-agency group (IAG) was established with the purpose of regulation and harmonization of statistical issues, including the strengthening of data collection. This group consists of the representatives of the most important international financial and statistical organizations. In October 2009, the IAG delivered their Report to the G-20, which identified the sectors where data gaps were to be filled and declared a set of twenty recommendations. These recommendations were to be implemented in the forthcoming years. They were divided into four diverse, but interdependent groups, related to resistance to shocks, financial sector risks, cross-border financial flows and official statistics communication. Within the third group of recommendations called "Sectoral and other financial and economic datasets (R15-R19)", we can find recommendation No. 19 on Real Estate Prices. It says that Working Group on Price Statistics becomes responsible for development of the handbook on real estate prices. In addition, available data on real estate prices should be examined and published by the Bank of International Settlements (BIS). The IAG will consider inclusion of real estate prices indicators in the Principal Global Indicators (PGI) internet site. The second stage of the G-20 Data Gaps Initiative (DGI-2) was launched in third quarter of 2015, introducing action plans which presented particular aims for the implementation of its twenty recommendations through the five-year time span (in other words, up to the year 2021). Regarding the real estate statistics, the IAG has issued two recommendations related to the areas of "Residential Property Prices (RPPI, recommendation II.17)" and "Commercial Property Prices (CPPI, recommendation II.18), with the main aim to produce a set of common headline residential property price indices, to encourage the production of historical time series and to develop a list of other related indicators. Speaking of commercial property price indices, large priorities were given to enhancement of the methodological guidance and encouragement of the dissemination of commercial property prices data (FSB/IMF, 2016).

Conclusions and action plans of the first and second phase of the G-20 Data Gaps Initiative put a lot of additional pressure on the official statisticians to produce many new statistical datasets within a medium-term period (producing the appropriate methodological manuals and handbooks at the same time) with the limited resources. 
In this sense, development of "experimental statistics" approach as a temporary solution during the transition period prior to the implementation of "official statistics" approach as a final solution was found as a reasonable approach.

The main research goal of this paper is to provide definition and show importance of the experimental statistics approach as a key part of the official statistics development stage. For the purpose of illustration of transition from the "experimental statistics" to the "official statistics" approach in Croatia, development process of the Residential property price index in Croatia has used for. Taking into account user needs, corresponding hypothesis set by authors is that is better to have any public disposable data during the experimental phase (accompanied by metadata) than no (official) data at all. On the other hand, methodological issues regarding the technical aspects of the construction of the residential property price index and hedonic regressions are not so important within the scope of this paper.

\section{Main features and evolution of the "experimental statistics" approach}

Experimental statistics is compiled using new data sources and methods (including estimates) and produced data series are in the testing phase, not yet fully developed in terms of coverage, data sources, and harmonised methodological definitions. Development of experimental statistics is an effort to expand and improve the way to respond to users' needs and a transition step towards achieving "official statistics" status of those series. From the dissemination of experimental statistics point of view, all users should be aware of the status and cautions of these series and particular limitations of each series can be explained by the accompanying methodological information (detailed metadata) and marked with a clearly visible "experimental statistics" logo. Determination of experimental statistics is largely a matter of statistical judgement, but experimental series are usually created under the defined statistical programme (as a new or modified version of existing official statistics). This statistic is still subject to verification in terms of their volatility and ability to meet customer needs and the rigorous quality standards. The main features of experimental statistics are related to development of new non-verified methods (subject to modification), partial coverage at the development stage and possibility for potential modification based on the user response. In order to enhance good and useful feedback from potential users, it is necessary to publish experimental statistics. Once the development process of experimental statistics is finished, we can propose to declare this statistics as official statistics on the basis of statistical quality judgement.

Since the early 2000's, the European Central Bank (ECB) has encouraged the national central banks to be active in development of experimental statistics area, to produce some experimental statistics and to transmit it to the ECB, with the main aim to support the ECB in compilation of the Euroarea and EU statistical aggregates and the national central banks to use it for their own purposes. Despite of all quality shortcomings, experimental statistics datasets are nonetheless regarded as sufficiently reliable for monetary policy and other purposes. It may therefore be topic of interest to other users outside the ECB.

Development and dissemination activities related to the ECB experimental data are strategically coordinated by the ESCB Working group on General Economic Statistics (WGGES) and operationally supported by the ECB Directorate General Statistics, Economic Statistics Section. Experimental data are disseminated via regular ECB publications and the ECB website. For example, the ECB releases at the moment experimental data on residential and commercial property prices, negotiated wages, 
industrial new orders, structural housing indicators and business demography, at the Euroarea level.

In order to develop new and improve existing statistics, Eurostat (most important official statistics producer in the EU) has also recently accepted the use of the "experimental statistics" approach as part of development process. Starting from midyear 2017, Eurostat has published experimental datasets on income inequality and poverty (flash indicators of annual changes of main income distribution indicators), skills mismatch (the gap between demand and supply of skills as well as conditions of workers, jobs or vacancies), distribution of income, consumption and wealth, food price monitoring (brings together data on price developments in the different steps of the supply chain), labour market transition statistics (movements of individuals between employment, unemployment and economic inactivity) and UNESCO World Heritage Sites (as a result from a big data project using Wikipedia statistics of visits as a source). The results of those experimental statistics are published on the Eurostat web site within a separate section, clearly labelled as "experimental". Datasets are different among each other in terms of timeliness, coverage (of population and number of member states covered) and publication format (Excel files, Report, Eurostat database, Ad hoc tool and Publication).

Each experimental dataset is published together with the accompanied explanation of the purpose of compilation, description of methodology and data sources used for the compilation, as well as produced time series. In order to achieve better quality of experimental statistics, Eurostat provides a possibility for the user feedback from other statisticians, economists, analysts and general public. They are counting on valuable comments or suggestions for improvements of the methods applied for the particular exercise, proposals of any other factors they should consider and other indicators or breakdowns that could be useful as early warnings and ideas about other indicators they should analyse for policy purposes, identification of other user needs and the main added value related to this data, etc.

In general, experimental statistics becomes official statistics when remaining methodological and quality related issues have settled down, when the coverage is appropriate, as well as user feedback indicates that these statistics are useful and credible. For example, Residential property price statistics was experimental statistics collected by the ESCB from the national central banks for more than a decade and those national datasets were used for the input for the calculation of Euroarea residential property price index by the ECB. At this time officially published methodological manuals and legal regulations were not prepared by international statistical organisations and the differences in terms of quality, coverage, timeliness and other principles of official statistics was existed.

\section{Literature review}

Taking into account the growing power of user needs, when significant progress was achieved, in 2013, the Eurostat had prepared and published supporting legal regulation and "Handbook on Residential Property Prices Indices", a comprehensive methodological guideline agreed at international level. This Handbook has been compiled by leading academics and by recognised experts in index number theory and RPPIs compilation, while development of Handbook was the joint responsibility of six international financial and statistical organizations, coordinated by the Eurostat (Eurostat, 2013). Also, the Handbook is finally published by the Eurostat and national statistical offices of the member states has obliged to produce national residential property prices indices and to start with the regular transmission of national data to the Eurostat. The majority of member states national statistical offices have produced 
up to now the RPPI data of the good quality and their national central banks have stopped to produce the same dataset previously labelled as "experimental".

Experimental data approach applied by the European Central Bank is described in Schubert (2012), while technical issues related with the measurement of hedonic residential property price indexes are outlined in Silver (2016).

Croatian National Bank started in 2007 to develop a hedonic real estate price index (HREPI), as an "experimental statistics". This work was started with development of the hedonic real estate price index (HREPI), based on Croatian association of real estate agencies (CAREA) database of executed transactions and their estimates. Very comprehensive description of the HREPI methodology is elaborated in Kunovac et al. (2008). While literature related with "experimental statistics" approach is relatively limited, a specific literature devoted to technical issues and econometric models used for hedonic regressions is more abundant. Various types of house price indices which took into account quality characteristics of real estate are described in Hill (2013). Some Croatian authors has been published interesting papers dealing with specific real estate market issues in Croatia, like distance of real estate to the city center (see Boras, 2013) and spatial elasticity of asked price in the Zagreb housing market, as described in Slišković and Tica (2016).

\section{Methodological and legal framework for the calculation of the Residential Property Price Index (RPPI) in the EU}

Macroeconomists, policymakers and central bankers require measures of residential property price inflation. It is necessary to identify bubbles, their determinants and financial instruments exposed to them and to analyse their relation with recessions. In 2002, the Eurostat started a series of pilot projects in cooperation with national statistical offices with main aim to develop an appropriate framework for compilation of residential property prices statistics at the EU level. At the end of pilot projects, the Eurostat published in 2013 "Handbook on Residential Property Price Indices (RPPIs)". Speaking of the terms used in Handbook, "residential property price", "house price" and "dwelling price" are synonyms and they describe the price developments of all residential properties acquired by individual households. Type of properties are distinguished, independently of their final use (owner occupied, for investment or second home purpose), on flats, detached houses, terraced houses, etc. Also, the land price is included in the house price. Residential property price index covers only actual transactions of dwellings at market prices. On the other hand, non-market prices are excluded, for example self-built dwellings. All purchases of new and existing dwellings are covered, as well as direct transactions with existing dwellings between households. Price of acquisition covers only the acquisition cost of a property itself, without any related costs related to the acquisition and major repairs. Construction of good RPPI's will help statisticians to overbridge existing methodological gaps. Two separate types of RPPI can be distinguished in Handbook: a constant quality price index at a particular moment in time and a constant quality price index for transactions during the reporting period. In general, construction of these two types of index will be different, mostly due to the weighting procedure (Eurostat, 2013). The four main approaches to constructing an RPPI are presented in the Handbook, the hedonic regression approach seems to be the most acceptable because it recognizes that heterogeneous goods that can be described by their attributes related to the structure and the location of the properties. The use of hedonic regression method is probably the best approach for construction of constant quality RPPIs for different types of residential property. At the same time, it is also the most 
data-intensive method. The main advantage of hedonic method is possibility to obtain estimates of the willingness of buyer to pay extra money for the different characteristics of real estate. The second advantage is the construction of quality-adjusted price indices. An additional methodological tool for the compilation of RPPI's was published by the Eurostat in 2017, publication entitled "Technical manual on Owner-Occupied Housing and House Price Indices". The legal framework for the calculation of RPPI's at the EU level is prescribed by the Commission Regulation (EU) No 93/2013 (Eurostat, 2013). According to stipulations, Member States shall provide quarterly house price indices to the Eurostat from the third quarter of 2012 (relating to the second quarter of 2012 data) onwards, within a $t+85$ day deadline after the end of the reporting quarter.

\section{Residential property price index in Croatia: methodological evolution}

Development of the RPPI in Croatia started in 2007 in the Croatian National Bank using an "experimental statistics" approach. The title of data series was "Hedonic Real Estate Price Index (HREPI)". The HREPI was published in the Croatian National Bank Bulletin on half-annual basis in the early beginnings, and on the quarterly basis later on (until the latest published data for Q2/2015). In meantime, due to obligatory requirements of Regulation (EU) No 93/2013, Croatian Bureau of Statistics has started with the development of the House Price Index (HPI), in accordance with the 2013 "Handbook on Residential Property Price Indices (RPPIs)", for the purpose of "official statistics". During the development process in the CBS, they were provided with the assistance of the Croatian National Bank staff regarding the econometrics and modelling issues. The CBS and the CNB has issued a joint press release on the first publication of HPI on January 20, 2016 (Croatian Bureau of Statistics, Croatian National Bank, 2016). Main methodological description of the HREPI and the HPI follows in the next two subsections.

\section{Experimental statistics - Croatian National Bank Hedonic Real Estate Price Index (HREPI)}

As was mentioned before, data on movement of real estate market were recognized as an important indicator for tracking the economic activity and the Croatian National Bank started in 2007 to develop a hedonic real estate price index (HREPI). The methodological work started on developing the HREPI by using source data on realised transactions and their estimates from the Croatian association of real estate agencies (CAREA) database. Due to the limited coverage of the transactions in the CAREA database, direct transactions between buyers and sellers on primary and secondary market are not included. An econometric model methodologically consistent with the Eurostat's Handbook was constructed for the purpose of creation of the HREPI. Starting from the first quarter of 1997, the HREPI was compiled and published quarterly and annually. Geographical breakdown was at the level of the Total (Republic of Croatia), the City of Zagreb (capital city of Croatia) and the Adriatic coast. The main idea was to calculate the index based on real estate characteristics. For this purpose, it is necessary to determine the so-called implicit prices, i.e. the prices of those characteristics (attributes). Their prices are estimated by simple econometric models, as there is no market for individual attributes of property and it makes possible to determine price adjusted for the impact of individual attributes of a given property. In practice, this attributes are related to geolocation (region, county, city and part of city) and qualitative characteristics (size in square meters, number of rooms, floor, total number of floors in building, existence of loggia or balcony, type of dwelling, date of 
construction and date of sale transaction, transaction price, type of heating, access to telephone and gas, etc. Additional variables are constructed for the recognition of new built residential real estate (less than five years from the date of completion), as well as attic, ground floor, ground level and basement position (Kunovac et al., 2008). The changes in pure prices are directly used to calculate the HREPI. According to this methodology, HREPI adjusts price changes for possible qualitative biases in the source data. A basic equation of the model and basis for all calculations in the HREPI construction is following (Kunovac et al., 2008):

$$
\ln p_{i t}=\alpha+\beta \ln m_{i}+\sum_{j=2}^{T} \delta_{j} D_{i j}+\sum_{j=1}^{l} \gamma_{j} X_{i j}+\varepsilon_{i}, \quad i=1, \ldots N
$$

where $a$ and $\beta$ are real constants, $D j, j=1, \ldots, T$ are time dummy variables, $\delta j$ and $\gamma j$ are regression coefficients, and हi random error.

\section{Official statistics - Croatian Bureau of Statistics House Price Index (HPI)}

Based on the Commission Regulation (EU) No 93/2013, a house price index (HPI) for Croatia has developed jointly by the Croatian Bureau of Statistics (CBS) and the Croatian National Bank (CNB). Finally, the quarterly HPI for Croatia is published on the website of the CBS on January, 20 2016. A new HPI has replaced the previous hedonic real estate price index (HREPI) in Eurostat's database. The coverage of HPI is broken down to total, new and existing dwellings. Speaking of geographical breakdown, the $\mathrm{HPI}$ has defined at the level of total (Republic of Croatia) and three additional geographic areas: the City of Zagreb (capital city), the Adriatic coast and Other (Croatian Bureau of Statistics, Croatian National Bank, 2016). The HPI covers all available data on residential property transactions (houses and flats/apartments) in Croatia based on the Tax Administration transaction data. This source has a better coverage of transactions than previous HREPI data source, because it covers also direct transactions between buyers and sellers on primary and secondary market. The index calculation starts with pre-defined hedonic regression models, where variables are defined on the basis of available real estate characteristics. The standard time-dummy hedonic regression was used for the calculation of indices prior to 2012. From the first quarter of 2012 onwards, rolling window time-dummy hedonic regression was used for the calculation because the extended set of real estate characteristics data becomes available. These sub-indices are finally aggregated to higher levels of aggregation using the Laspeyres-type formula (Croatian Bureau of Statistics / Croatian National Bank, 2016).

\section{The main methodological differences between HREPI and HPI}

Both hedonic indices (new HPI and the old HREPI) are very similar and based on hedonic regression models recommended by Eurostat Handbook. The main methodological difference arise from the use of different data sources for the calculation. Previous HREPI was compiled using the sample of transactions collected by CAREA and their actual price movements, while new HPI also register actual price movements, but derived from significantly detailed and comprehensive Tax administration database. A good feature of the old HREPI is that enables estimation of historical data series, because the reliable data of the Tax Administration are available from the last quarter of 2007 onwards. New established HPI is based on a different stratification of the sample compared with the old HREPI. Also, separate breakdown is introduced for new and existing real estate property. In generally, HPI for the Republic 
of Croatia was calculated as a result of the changes of six real estate price sub-indices for three provisionally defined Croatian geographical areas. On the other hand, due to the limited availability of data from previous data source, the HREPI was constructed for only two geographical areas. Methodological comparability of the new HPI and the old HREPI is limited due to different stratification and use of the different data sources. The HPI is constructed using a full coverage of transactions registered with the tax authorities, while HREPI aligned on the sample of transactions reported by the CAREA, mainly for two geographical areas. The relative share of these areas is very different. Relative share of the City of Zagreb was approximately $70 \%$ in the old HREPI, compared to approximately $30 \%$ in the new HPI. Speaking of the characteristics of the real estate (geolocation and other qualitative characteristics) used for the calculation of hedonic index, all characteristics used for the HREPI were explicitly listed in Kunovac et al. (2008), while characteristics used for the HPI were not officially published, but we can assume that they are almost the same, as used for the HREPI construction. A short overview of the methods and data used for construction of the HREPI and HPI is shown in Table 1, while comparison of data series developments of the HREPI and the HPI is shown by Figure 1.

Table 1 Overview of the methods and data used for construction of the HREPI and $\mathrm{HPI}$

\begin{tabular}{|c|c|c|}
\hline & HREPI & $\mathrm{HPI}$ \\
\hline Methodology & $\begin{array}{l}\text { Hedonic regression models } \\
\text { recommended by Eurostat }\end{array}$ & $\begin{array}{l}\text { Hedonic regression models } \\
\text { recommended by Eurostat }\end{array}$ \\
\hline Data coverage & $\begin{array}{l}\text { Actual price movements of } \\
\text { the sample of tansactions - } \\
\text { Real Estate Association }\end{array}$ & $\begin{array}{c}\text { Detailed and comprehensive } \\
\text { database - Tax Administration } \\
\text { (transactions in the trading of real } \\
\text { estate) }\end{array}$ \\
\hline $\begin{array}{l}\text { Time period } \\
\text { coverage }\end{array}$ & $\begin{array}{l}\text { First quarter of } 1997 \text { to } \\
\text { second quarter of } 2015\end{array}$ & Fourth quarter of 2007 onwards \\
\hline $\begin{array}{c}\text { Level of } \\
\text { aggregation }\end{array}$ & $\begin{array}{c}\text { Republic of Croatia, City of } \\
\text { Zagreb, Adriatic Coast }\end{array}$ & $\begin{array}{c}\text { Republic of Croatia, City of } \\
\text { Zagreb, Adriatic Coast and Other }\end{array}$ \\
\hline $\begin{array}{c}\text { Real estate } \\
\text { characteristics }\end{array}$ & $\begin{array}{l}\text { Region, county, city and } \\
\text { part of the city, size in } \\
\text { square meters, number of } \\
\text { rooms, floor, total number of } \\
\text { floors in building, position } \\
\text { (attic, ground floor, ground } \\
\text { level and basement), } \\
\text { existence of loggia or } \\
\text { balcony, type of dwelling, } \\
\text { date of construction and } \\
\text { date of sale transaction, } \\
\text { transaction price, type of } \\
\text { heating, access to } \\
\text { telephone and gas, etc. }\end{array}$ & $\begin{array}{l}\text { Not officially released, it would be } \\
\text { almost the same as used for the } \\
\text { construction of the HREPI }\end{array}$ \\
\hline $\begin{array}{l}\text { Categories of } \\
\text { expenditure }\end{array}$ & - & New dwellings, Existing dwellings \\
\hline
\end{tabular}

Source: Croatian National Bank, Croatian Bureau of Statistics, 2016. 


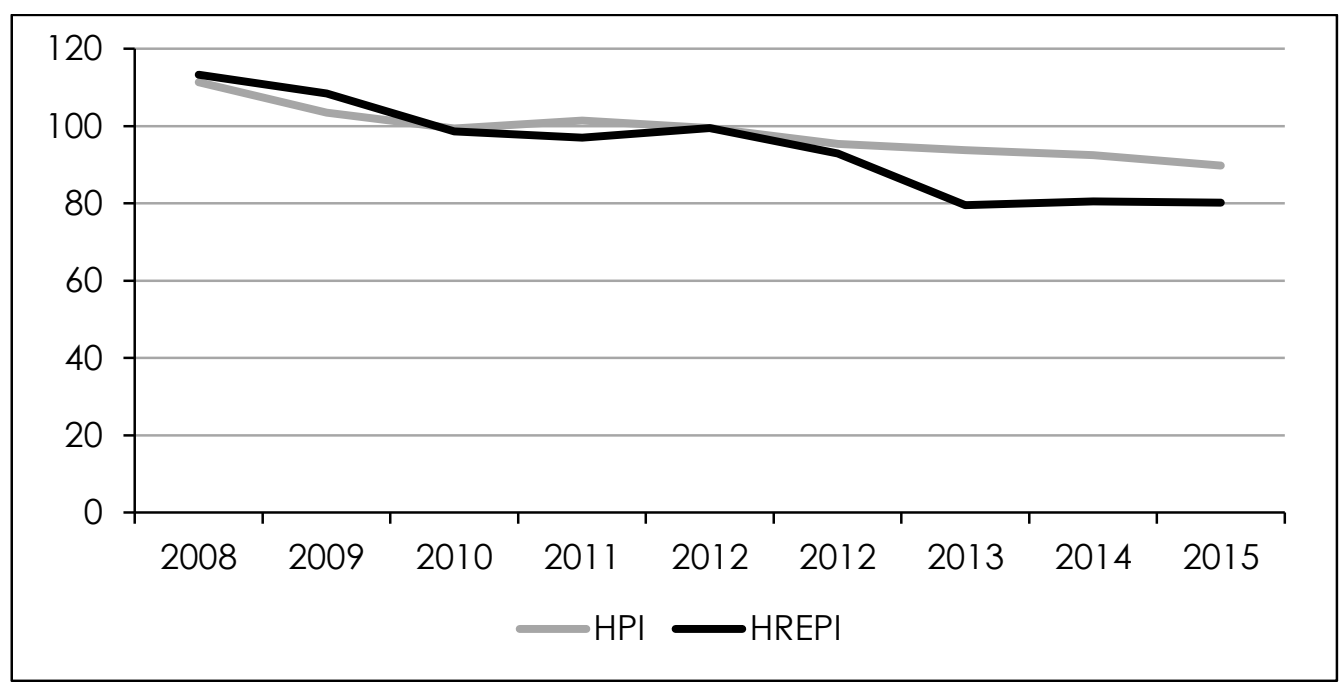

Figure 1 Developments of the HPI and the HREPI during the Q1/2008 - Q2/2015 period $(\varnothing 2010=100)$

Source: Croatian National Bank, Croatian Bureau of Statistics, 2016, Authors' creation.

\section{Conclusions}

Since the appearance of the last 2007 global economic crisis and the following consequences, a growing demand for better, detailed and more timely data under limited resources for compilers as well as reporting agents is observed. The concept of experimental statistics becomes more relevant and recognised as a new way of increasing the efficiency of official statistics production, despite of the somewhat lower quality in terms of coverage, data sources, harmonised definitions and sometimes heavily use of estimation techniques and expert assumptions. The use of experimental statistics in the area of real estate can help statisticians to bridge the limited availability of official data, in particular given its traditionally good timeliness that could provide a quick snapshot of currently perceived market conditions. We can generally conclude that publication of non-harmonized experimental statistics results, together with explanatory metadata is more preferable from the point of view of users than to have nothing produced by official statistics, what also confirms our initial hypothesis. In that sense, central bank of Croatia has developed an experimental hedonic real estate price index (HREPI), based on the CAREA database as a data source. Since 2013, when Commission Regulation (EU) No 93/2013 and Eurostat's "Handbook on Residential Property Price Indices - RPPI" came into force, Croatian Bureau of Statistics in cooperation with the Croatian National Bank jointly prepared methodological framework for the construction of House price index (HPI) as an official statistics index. During the overlapping time span period Q1/2008 - Q2/2015, we can observe similar patterns of both series until the last quarter of 2012 , while the falling pattern of the HPI series was lower compared with the HREPI series during the rest of the observed period. This is mainly due to the use of a very detailed and comprehensive new data source, database of the Tax Administration (transactions in the trading of real estate) for the purpose of construction of HPI. Nevertheless, the main benefit of the existing old HREPI series is related to the existence of historical data for the first quarter of 1997 until the last quarter of 2007 period. The second and no less important benefit of the development process from HREPI to HPI was the establishment and increased cooperation of experts from Croatian Bureau of Statistics and Croatian National Bank. 


\section{References}

1. Boras, T. (2013). Udaljenost i dostupnost centra grada kao determinante traženih cijena stambenog prostora. Ekonomski pregled, Vol. 64, No. 6, pp. 563-586.

2. Croatian Bureau of Statistics, Croatian National Bank (2016). Press Release on Issuing a House Price Index (HPI). Available at https://www.dzs.hr/Eng/important/PressCorner/Press\%20release\%20on\%20issuing\%20house \%20price\%20index.pdf [01 October 2018].

3. Eurostat (2013). Handbook on Residential Property Price Indices (RPPIs). Available at http://ec.europa.eu/eurostat/documents/3859598/5925925/KS-RA-12-022-EN.PDF October 2018].

4. FSB/IMF (2016). Second Phase of the G-20 Data Gaps Initiative (DGI-2) - First Progress Report. Available at https://www.imf.org/external/np/g20/pdf/2016/090216.pdf [01 October 2018].

5. Hill, R. J. (2013). Hedonic Price Indexes for Residential Housing: A Survey, Evaluation and Taxonomy. Journal of Economic Surveys, Vol. 27, No. 5, pp. 879-914.

6. Kunovac, D., Đozović, E., Lukinić, G., Pufnik, A. (2008). Use of the Hedonic Method to Calculate an Index of Real Estate Prices in Croatia. Available at http://www.hnb.hr/documents/20182/121648/w-019.pdf/ea81e78f-0f90-4260-905bfbleaad5bfaa [01 October 2018].

7. Schubert, A. (2012). Experimental data as part of the ECB's statistical production and dissemination policy. Available at http://q2012.gr/articlefiles/sessions/26.2-ExperimentalstatisticsECB-AurelSchubert.pdf [01 October 2018].

8. Silver, M. (2016). How to better measure hedonic residential property price indexes. Available at https://www.imf.org/ /media/Websites/IMF/imported-full-textpdf/external/pubs/ft/wp/2016/_wp16213.ashx [01 October 2018].

9. Slišković, T., Tica, J. (2016). Prostorna elastičnost traženih cijena stanova na stambenom tržištu grada Zagreba. Ekonomska misao i praksa, Vol. 11, No. 1, pp. 23-44.

\section{About the authors}

Davor Galinec, PhD, works as a chief advisor at the Croatian National Bank, Statistics Area, and as a university professor at the Dag Hammarskjöld University College of International Relations and Diplomacy in Zagreb, Croatia. He finished a graduate (1992), a postgraduate (1997) and a PhD (2007) programme at the Faculty of Economics and Business of the University of Zagreb, Croatia. He publishes in scientific and professional journals as the author or co-author of books and papers from the areas of international economics, public finance and statistics and actively participates in international conferences and scientific research projects. The author can be contacted at davor.galinec@hnb.hr.

Jadranka Vuglar, MSc in Economics, finished a graduate and a postgraduate programme at the Faculty of Economics and Business Zagreb of the University of Zagreb, Croatia. Starting as a trainee within the National Accounts Sector at the Croatian Bureau of Statistics, during 17 years, she has gained extensive experience as a compiler, expert, project leader and methodologist of the national accounts aggregates. Currently she is working as an advisor at the Croatian National Bank in the General Economic and External Statistics Department of the Statistics Area. The author can be contacted at jadranka.vuglar@hnb.hr.

Dario Crrtila is a professional specialist of international relations and diplomacy and works as a teaching assistant at the Dag Hammarskjöld University College of International Relations and Diplomacy in Zagreb, Croatia. He completed the Undergraduate Professional Study Programme of International Relations and Diplomacy in 2013 and the Specialist Graduate Professional Study Programme of International Relations and Diplomacy in 2015. The author can be contacted at dario.cvrtila@diplomacija.hr. 